\title{
Sodium and Potassium tert-Butyl Peroxide Hydrates: Crystal Structure and Properties
}

\author{
A. G. Medvedev ${ }^{a}$, M. Yu. Sharipov ${ }^{a}$, A. A. Mikhaylov ${ }^{a}$, D. A. Grishanov ${ }^{a}$, \\ A. V. Churakov ${ }^{a}$, and P. V. Prikhodchenko ${ }^{a}$, * \\ ${ }^{a}$ Kurnakov Institute of General and Inorganic Chemistry, Russian Academy of Sciences, Moscow, Russia \\ *e-mail:prikhman@gmail.com \\ Received May 5, 2021; revised May 17, 2021; accepted May 18, 2021
}

\begin{abstract}
Sodium and potassium tert-butyl peroxide hydrates $2 \mathrm{Na}^{+} \cdot 2 \mathrm{C}_{4} \mathrm{H}_{9} \mathrm{O}_{2}^{-} \cdot 7 \mathrm{H}_{2} \mathrm{O}$ (I) and $2 \mathrm{~K}^{+}$. $2 \mathrm{C}_{4} \mathrm{H}_{9} \mathrm{O}_{2}^{-} \cdot 4 \mathrm{H}_{2} \mathrm{O}$ (II) were prepared. According to X-ray diffraction data (CIF files CCDC no. 2081025 (I) and no. 2081024 (II)), the compounds are coordination polymers in which alkali metal atoms have C.N.(Na) of 6 or C.N.(K) of 6 and 8 . The crystal packings comprise layers with clearly defined hydrophobic surfaces consisting of hydrocarbon groups and hydrophilic inner areas including water molecules, alkali metal cations, and peroxy groups of the tert-butyl peroxide anions. Compounds were characterized by vibrational spectroscopy, ${ }^{1} \mathrm{H},{ }^{13} \mathrm{C}$ NMR spectroscopy, thermogravimetry, and differential scanning calorimetry.
\end{abstract}

Keywords: organic peroxides, coordination polymers, X-ray diffraction, hydrogen bonds, tert-butyl hydroperoxide, peroxide complexes

DOI: $10.1134 / \mathrm{S} 1070328421100043$

\section{INTRODUCTION}

The preparation methods and properties of nonsolvated organic peroxides of group I metals $\mathrm{Li}, \mathrm{Na}$, and $\mathrm{K}$ (salts of organic hydroperoxides) were considered in detail in a review [1]. Organic alkali metal peroxides are used as efficient oxidants [2, 3], in particular for the asymmetric epoxidation of olefins [4-6], and as the starting compounds for the synthesis of organic peroxides of other group elements [7-9]. Often, alkali metal peroxides are formed in situ during the syntheses. The use of the initial liquid organic hydroperoxides in some reactions is restricted by their low stability.

Organic alkali metal peroxides were synthesized previously, including alkali metal salts (lithium, sodium, potassium) of tert-butyl hydroperoxide containing no solvate molecules [10-12]. However, these compounds are hygroscopic and, therefore, unstable [1]. Apparently, this accounts for the absence of X-ray diffraction data for sodium and potassium tert-butyl peroxides containing no other organic molecules. Currently, the Cambridge Crystallographic Data Centre includes only two crystal structures containing potassium and sodium tert-butyl peroxides stabilized by NNNN-macrocycles [13] (ref. codes DERKET and DERXAC, respectively). In this respect, the syn- thesis and characterization of sodium and potassium tert-butyl peroxides appears relevant.

\section{EXPERIMENTAL}

Commercial reagents and solvents were used for the synthesis as received: sodium amide $(95 \%$, Acros Organics), tert-butyl hydroperoxide (70\% aqueous solution, Acros Organics), potassium hydroxide (analytical grade, Khimmed), toluene (special purity grade, Khimmed), ethanol (95\%, Acros Organics), and diethyl ether (analytical grade, Khimmed). The solution of tert-butyl hydroperoxide in diethyl ether was prepared from the aqueous solution.

Synthesis of $2 \mathrm{Na}^{+} \cdot 2 \mathrm{C}_{4} \mathrm{H}_{9} \mathrm{O}_{2}^{-} \cdot \mathbf{7} \mathrm{H}_{2} \mathrm{O}$ (I). A $50 \%$ solution of tert-butyl hydroperoxide $(1.081 \mathrm{~g}, 6 \mathrm{mmol})$ in diethyl ether was added with stirring to a solution of $\mathrm{NaNH}_{2}(0.234 \mathrm{~g}, 6 \mathrm{mmol})$ in toluene $(10 \mathrm{~mL})$. The reaction mixture was evaporated on a rotary evaporator in vacuum with gradual increase in the water bath temperature to $50^{\circ} \mathrm{C}$. The product was dissolved with heating in $95 \%$ ethanol $(5 \mathrm{~mL})$ and filtered. After $1 \mathrm{~h}$, colorless prismatic crystals were formed. The crystals 
were separated from the mother liquor by filtration and dried in air. The yield of I was $0.70 \mathrm{~g}(67 \%)$.

For $\mathrm{C}_{8} \mathrm{H}_{32} \mathrm{O}_{11} \mathrm{Na}_{2}$ (I)

$\begin{array}{lll}\text { Anal. calcd., \% } & \text { C, } 27.42 & \text { H, } 9.21 \\ \text { Found, \% } & \text { C, } 27.34 & \text { H, } 9.27\end{array}$

IR $\left(v, \mathrm{~cm}^{-1}\right): 3498 \mathrm{~s}, 3200$ s.br, 3065 s.br, $2978 \mathrm{~s}$, $2932 \mathrm{~s}, 2286$ w.br, $1722 \mathrm{w}, 1680 \mathrm{~m}, 1633 \mathrm{~m}, 1472 \mathrm{~m}$, $1440 \mathrm{~m}, 1384 \mathrm{~m}, 1358 \mathrm{~s}, 1326 \mathrm{w}, 1253 \mathrm{~m}, 1241 \mathrm{~m}$, 1195 s, 1085 w.br, 920 w, 895 m, 841 m, 755 w, 575 s.br, 526 s.br, $473 \mathrm{~m}$.

${ }^{1} \mathrm{H}$ NMR $\left(\mathrm{CD}_{3} \mathrm{OD} ; \delta, \mathrm{ppm}\right): 1.23$ s. $\left(9 \mathrm{H}, \mathrm{CH}_{3}\right) \cdot{ }^{13} \mathrm{C}$ NMR (CD $\mathrm{OD} ; \delta, \mathrm{ppm}): 25.06 \mathrm{~m}\left(\mathrm{CH}_{3}\right), 79.13(\mathrm{C})$.

Synthesis of $\mathbf{2} \mathrm{K}^{+} \cdot \mathbf{2} \mathrm{C}_{4} \mathrm{H}_{\mathbf{9}} \mathrm{O}_{2}^{-} \cdot \mathbf{4} \mathrm{H}_{2} \mathrm{O}$ (II). A solution of potassium hydroxide $(0.5 \mathrm{~g}, 7.58 \mathrm{mmol})$ in ethanol $(5$ $\mathrm{mL}$ ) was added with stirring to a $70 \%$ aqueous solution of tert-butyl hydroperoxide $(0.975 \mathrm{~g}, 7.58 \mathrm{mmol})$. The reaction mixture was evaporated on a rotary evaporator. in vacuum The crystalline product was washed with anhydrous ethanol and dried in air. The yield of II was $0.85 \mathrm{~g}(68 \%)$.

For $\mathrm{C}_{8} \mathrm{H}_{26} \mathrm{O}_{8} \mathrm{~K}_{2}$ (II)

Anal. calcd., \%

C, 29.25

H, 7.98

Found, \%

C, 29.32

H, 8.07

IR $\left(v, \mathrm{~cm}^{-1}\right): 3491 \mathrm{~s}, 3216$ s.br, 2970 s, 2929 s, 2877 s, 1670 m.br, 1634 m.br, 1472 w, 1443 w, 1383 w, $1358 \mathrm{~s}, 1303 \mathrm{~m}, 1241 \mathrm{~m}, 1193 \mathrm{~s}, 1027 \mathrm{w}, 921 \mathrm{w}, 896 \mathrm{~m}$, 840 m, 750 w, 562 m.br, 524 m, 472 w.

${ }^{1} \mathrm{H}$ NMR $\left(\mathrm{CD}_{3} \mathrm{OD} ; \delta\right.$, ppm): $1.23 \mathrm{~s}\left(9 \mathrm{H}, \mathrm{CH}_{3}\right) \cdot{ }^{13} \mathrm{C}$ NMR (CD $\mathrm{OD} ; \delta, \mathrm{ppm}): 25.10 \mathrm{~m}\left(\mathrm{CH}_{3}\right), 79.13(\mathrm{C})$.

IR spectra were recorded on a Jasco FT/IR4600LE FTIR spectrophotometer in the attenuated total reflectance (ATR) mode in the $400-4000 \mathrm{~cm}^{-1}$ range.

Elemental analysis was performed on a EuroVector EA3000 C, H, N-analyzer.

The thermal stability of compounds was studied by thermogravimetry (TGA) and differential scanning calorimetry (DSC) on Shimadzu DSC-60 and DTG60 instruments, respectively, in an argon atmosphere in the temperature range of $25-350^{\circ} \mathrm{C}$ at a heating rate of $5^{\circ} \mathrm{C} / \mathrm{min}$.

${ }^{1} \mathrm{H}$ and ${ }^{13} \mathrm{C}$ NMR spectra were recorded on a Bruker Avance 600 spectrometer (14.1 T) operating at $600.03\left({ }^{1} \mathrm{H}\right)$ and $150.90\left({ }^{13} \mathrm{C}\right) \mathrm{MHz}$ using TMS as the internal standard.

Powder X-ray diffraction data of I and II were collected at room temperature on a Bruker D8 Advance diffractometer using $\mathrm{Cu} K_{\alpha}$ radiation $(\lambda=1.5418 \AA ̊$ ). The X-ray diffraction patterns were measured in the $5^{\circ}-60^{\circ} 2 \theta$ range under the following conditions: $X$-ray tube operating voltage of $40 \mathrm{kV}$, anode current of
$40 \mathrm{~mA}$, radius of the goniometer of $280 \mathrm{~mm}$, the angle step of the goniometer of $0.02^{\circ}$, acquisition time of $0.5 \mathrm{~s} / \mathrm{step}$. The resulting X-ray diffraction patterns were analyzed using the DiffracSuite software package.

Single crystal X-ray diffraction study of I and II was carried out on a Bruker D8 Venture automated diffractometer equipped with a Photon II detector (Mo $K_{\alpha}$ radiation, $\lambda=0.71073 \AA$ graphite monochromator, $\omega$-scan mode) at $150 \mathrm{~K}$. The absorption corrections were applied using the measured intensities of equivalent reflections [14]. The structures of I and II were solved by direct methods and refined by fullmatrix anisotropic least squares method on $F^{2}$ for all non-hydrogen atoms [15]. All hydrogen atoms were found from difference Fourier maps and refined isotropically. The crystallographic data and structure refinement details for I and II are summarized in Table 1; selected bond lengths and bond angles are given in Table 2.

The structures of I and II are deposited with the Cambridge Crystallographic Data Centre (nos. 2081025 and 2081024 respectively; deposit@ccdc. cam.ac.uk or http://www.ccdc.cam.ac.uk/).

\section{RESULTS AND DISCUSSION}

The colorless crystals of the sodium salt of tertbutyl peroxide hydrate $2 \mathrm{Na}^{+} \cdot 2 \mathrm{C}_{4} \mathrm{H}_{9} \mathrm{O}_{2}^{-} \cdot 7 \mathrm{H}_{2} \mathrm{O}$ (I) were obtained by recrystallizing the product formed in the reaction of a diethyl ether solution of tert-butyl hydroperoxide with a toluene solution of sodium amide from $95 \%$ ethanol. The compound crystallizes in space group $C 2 / c$ (Table 1). The sodium cation has a distorted octahedral environment consisting of oxygen atoms of six water molecules with $\mathrm{Na}-\mathrm{O}$ distances ranging from $2.3246(5)$ to $2.4943(8) \AA$ (Fig. 1). The $\mathrm{ONaO}$ angles formed by oxygen atoms in trans-positions are in the range of $160.08(2)^{\circ}-166.74(3)^{\circ}$. Two water molecules in the cation coordination environment act as bridging ligands between neighboring sodium cations, thus forming infinite $\left[\mathrm{Na}\left(\mathrm{H}_{2} \mathrm{O}\right)_{6}\right]_{n}^{+}$ polymer chains extended along the $b$ axis with $\mathrm{Na}$... Na distances of 3.499(1) and 3.501(1) $\AA$. The third water molecule forms a bridge between sodium cations of neighboring chains, thus combining the chains into $2 \mathrm{D}$ layers in the $b c$ plane (Fig. 2) with the Na...Na distance of $3.990 \AA$.

The $\mathrm{O}-\mathrm{O}$ distance in the peroxide group of the $\mathrm{C}_{4} \mathrm{H}_{9} \mathrm{O}_{2}^{-}$anion is $1.4807(8) \AA$, which is in line with analogous distances in organic peroxides. The oxygen atoms of the anion act as acceptors for the hydrogen bonds with neighboring water molecules (Fig. 3). The $\mathrm{O}(12)$ atom is involved in four medium-strength hydrogen bonds with O...O contacts of 2.6994(9)2.7570 (9) $\AA$, while the $\mathrm{O}(11)$ atom is involved in two weaker H-bonds $(2.9992(10)-3.0515(9) \AA)$. To our 
Table 1. Crystal data and X-ray experiment details for I and II

\begin{tabular}{|c|c|c|}
\hline \multirow{2}{*}{ Parameter } & \multicolumn{2}{|c|}{ Value } \\
\hline & $\mathbf{I}$ & II \\
\hline Molecular formula & $\mathrm{C}_{8} \mathrm{H}_{32} \mathrm{O}_{11} \mathrm{Na}_{2}$ & $\mathrm{C}_{8} \mathrm{H}_{26} \mathrm{O}_{8} \mathrm{~K}_{2}$ \\
\hline$M$ & 350.31 & 328.49 \\
\hline Sample size, $\mathrm{mm}$ & $0.40 \times 0.40 \times 0.20$ & $0.15 \times 0.05 \times 0.01$ \\
\hline Temperature, $\mathrm{K}$ & 150 & 150 \\
\hline System & Monoclinic & Triclinic \\
\hline Space group & $C 2 / c$ & $P \overline{1}$ \\
\hline$a, \AA$ & 27.0861(11) & $5.988(2)$ \\
\hline$b, \AA$ & $6.0315(2)$ & $10.621(4)$ \\
\hline$c, \AA$ & $11.3877(5)$ & $13.448(5)$ \\
\hline$\alpha$, deg & 90 & $70.631(11)$ \\
\hline$\beta, \operatorname{deg}$ & $98.1531(14)$ & 87.984(11) \\
\hline$\gamma, \operatorname{deg}$ & 90 & $85.981(11)$ \\
\hline$V, \AA^{3}$ & $1841.60(13)$ & $804.9(5)$ \\
\hline$Z$ & 4 & 2 \\
\hline$\rho$ (calcd. $), \mathrm{g} / \mathrm{cm}^{3}$ & 1.263 & 1.355 \\
\hline$\mu\left(\mathrm{Mo}_{\alpha}\right), \mathrm{mm}^{-1}$ & 0.152 & 0.61 \\
\hline$F(000)$ & 760 & 352 \\
\hline Range of $\theta$, deg & $3.04-30.48$ & $2.91-30.77$ \\
\hline Total number of reflections & 14306 & 7636 \\
\hline Number of unique reflections $\left(R_{\text {int }}\right)$ & $2692(0.0323)$ & $3029(0.0565)$ \\
\hline Number of refined parameters & 160 & 267 \\
\hline$R_{1}(I>2 \sigma(I))$ & 0.0284 & 0.0526 \\
\hline$w R_{2}$ (all data) & 0.0769 & 0.0937 \\
\hline GOOF & 1.045 & 1.086 \\
\hline$\Delta \rho_{\min } / \Delta \rho_{\max }, \mathrm{e} / \AA^{3}$ & $-0.162 / 0.401$ & $-0.377 / 0.533$ \\
\hline
\end{tabular}

Table 2. Selected bond lengths ( $\AA$ ) and angles (deg) for I and II*

\begin{tabular}{|c|c|c|c|}
\hline Bond & $d, \AA$ & Bond & $d, \AA$ \\
\hline \multicolumn{4}{|c|}{$\mathbf{I}$} \\
\hline \multicolumn{4}{|c|}{ II } \\
\hline $\mathrm{K}(1)-\mathrm{O}$ & $2.591(2)-2.896(2)$ & $\mathrm{O}(11)-\mathrm{O}(12)$ & $1.477(2)$ \\
\hline $\mathrm{K}(2)-\mathrm{O}$ & $2.672(2)-3144(2)$ & $\mathrm{O}(21)-\mathrm{O}(22)$ & $1.483(2)$ \\
\hline Angle & $\omega$, deg & Angle & $\omega$, deg \\
\hline \multicolumn{4}{|c|}{ I } \\
\hline $\mathrm{ONa}(1) \mathrm{O}(c i s)$ & $84.18(2)-106.00(3)$ & $\mathrm{C}(1) \mathrm{O}(11) \mathrm{O}(12)$ & $110.41(6)$ \\
\hline $\mathrm{ONa}(1) \mathrm{O}($ trans $)$ & $160.08(2)-166.74(3)$ & & \\
\hline $\mathrm{OK}(1) \mathrm{O}(c i s)$ & $68.62(7)-128.71(7)$ & OK(2)O(trans) & $130.12(7)-157.88(7)$ \\
\hline $\mathrm{OK}(1) \mathrm{O}($ trans $)$ & $144.35(7)-168.58(7)$ & $\mathrm{C}(11) \mathrm{O}(11) \mathrm{O}(12)$ & $110.8(2)$ \\
\hline $\mathrm{OK}(2) \mathrm{O}(c i s)$ & $31.11(5)-110.05(6)$ & $\mathrm{C}(21) \mathrm{O}(21) \mathrm{O}(22)$ & $110.8(2)$ \\
\hline
\end{tabular}




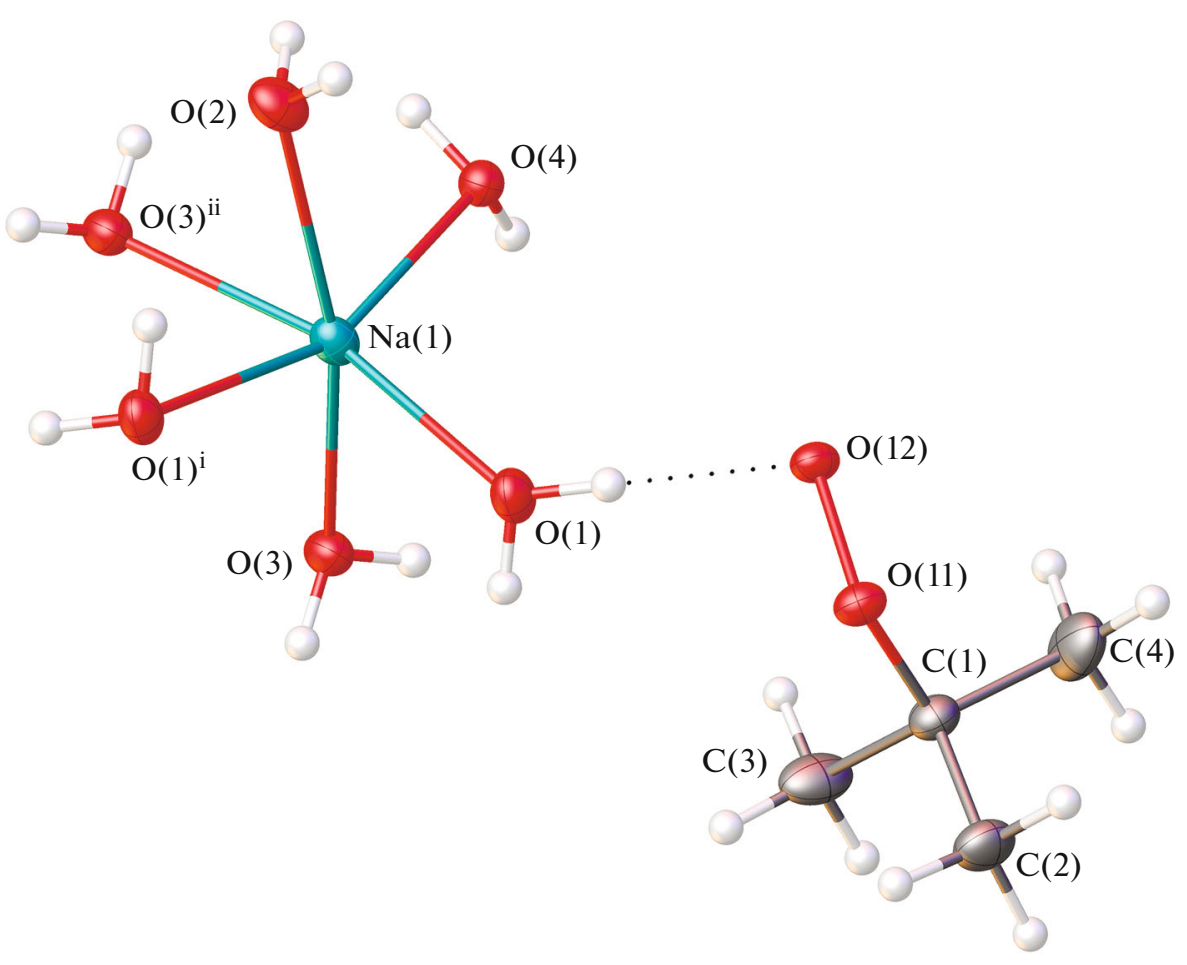

Fig. 1. Fragment of the crystal structure of $\mathbf{I}$. Thermal ellipsoids are drawn at $50 \%$ probability level. H-bonds are shown by dashed lines. Symmetry codes used to generate equivalent atoms: ${ }^{\mathrm{i}} 1-x, 1-y, 1-z ;{ }^{\mathrm{ii}} 1-x,-y, 1-z$.

knowledge, compound $\mathbf{I}$ is the first example of a structure in which the organic peroxide anion is not coordinated to a metal.

The crystal packing of I consists of double layers perpendicular to the $a$ axis, with hydrophobic surfaces being formed by the hydrocarbon groups of the $\mathrm{C}_{4} \mathrm{H}_{9} \mathrm{O}_{2}^{-}$, anions and hydrophilic inner areas containing peroxide groups of the anions and $\left[\mathrm{Na}\left(\mathrm{H}_{2} \mathrm{O}\right)_{6}\right]_{n}^{+}$ layers (Fig. 4). The neighboring layers form threedimensional structures via weak van der Waals contacts.

The reactions of tert-butyl hydroperoxide with potassium hydroxide in water gives the hydrate of the tert-butyl peroxide potassium salt $2 \mathrm{~K}^{+} \cdot 2 \mathrm{C}_{4} \mathrm{H}_{9} \mathrm{O}_{2}^{-}$. $4 \mathrm{H}_{2} \mathrm{O}$ (II). Compound II crystallizes in the space group $P \overline{1}$ (Table 1$)$. The crystallographically independent region includes two potassium cations, four water molecules, and two tert-butyl peroxide anions, one of which is coordinated to potassium cations $\left(\mu_{2}-\eta^{1}, \eta^{2}-\right.$ $\mathrm{OO}^{t} \mathrm{Bu}$ type of coordination [16]) and participates in the formation of one $\mathrm{H}$-bond as a proton acceptor. The other anion is involved only in hydrogen bonding to water molecules (Table 2, Fig. 5). The environment of the $K(1)$ cation consists of six oxygen atoms, two of which belong to the coordinated tert-butyl peroxide anions $\mathrm{C}_{4} \mathrm{H}_{9} \mathrm{O}_{2}^{-}\left(\mathrm{O}(11)^{\mathrm{i}}\right.$ and $\left.\mathrm{O}(12)\right)$ and the other belong to four coordinated water molecules $(\mathrm{O}(2)$,
$\mathrm{O}(3), \mathrm{O}(4)$, and $\left.\mathrm{O}(2)^{\mathrm{i} v}\right)$. The $\mathrm{K}(2)$ environment is composed of eight oxygen atoms, two of which also belong to the anion $((\mathrm{O}(11)$ and $\mathrm{O}(12))$ and six of which belong to water molecules. The oxygen atoms of water molecules $\left(\mathrm{O}(2)^{\mathrm{iv}}\right.$ and $\left.\mathrm{O}(3)\right)$ and the anion $(\mathrm{O}(12))$ occupy bridging positions between the $\mathrm{K}(1)$ and $K(2)$ cations, with $K(1) \ldots K(2)$ distances being 3.638(1) and 3.731(1) $\AA$, which gives rise to chains along the $a$ axis. Two $\mathrm{K}(1)$ cations of neighboring chains, like $\mathrm{K}(2)$, are joined by two bridging water molecules, thus forming layers in the $a b$ plane (Fig. 6), with $K(1) \ldots K(1)$ and $K(2) \ldots K(2)$ distances being 3.484(2) and 4.345(2) A, respectively (Table 2).

The $\mathrm{O}(11)-\mathrm{O}(12)$ distance in the peroxide group of the $\mathrm{C}_{4} \mathrm{H}_{9} \mathrm{O}_{2}^{-}$, anion coordinated to the cation is $1.477(2) \AA$, while in the anion whose oxygen atoms are involved only in $\mathrm{H}$-bonds, the $\mathrm{O}(21)-\mathrm{O}(22)$ length is 1.483(2) A. Both distances are similar to this distance found in $\mathbf{I}$. The $\mathrm{O}(22)$ atom serves as an acceptor of four hydrogen bonds, while the $\mathrm{O}(21)$ atom is an acceptor of two hydrogen bonds (Fig. 7). The O...O distances for $\mathrm{H}$-bonds involving $\mathrm{O}(22)$ atom amount to 2.699(3)-2.849(3) $\AA$, whereas in the case of $\mathrm{O}(21)$, these distances are 2.791(3) and 3.042(3) $\AA$. The $\mathrm{O}(11)$ atom participates in the formation of a short $\mathrm{H}$ bond with a water molecule $(2.554(3) \AA)$.

The crystal structure of II, like that of I, consists of double layers parallel to the $a b$ plane, which have 

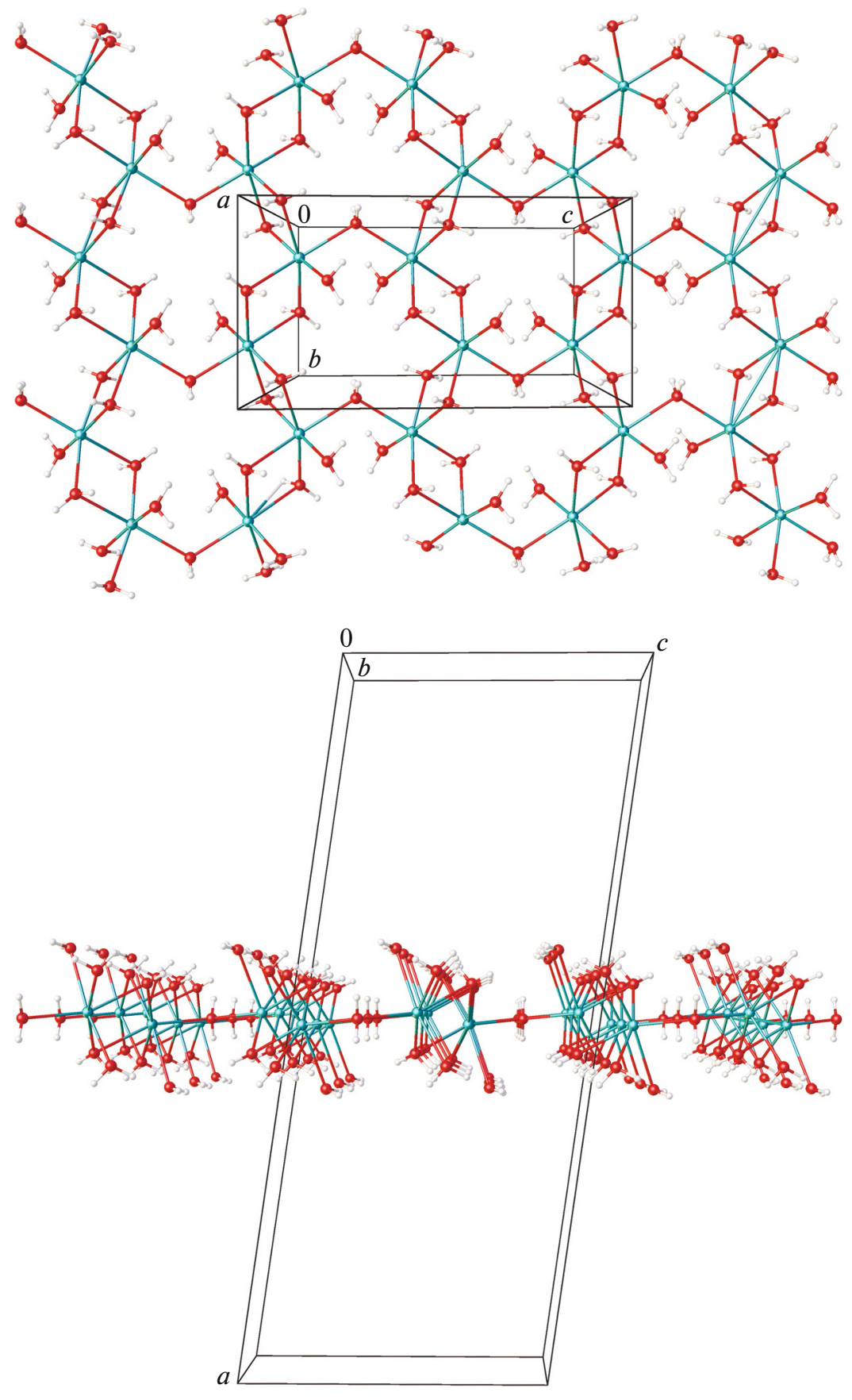

Fig. 2. Layers in the $b c$ plane formed by $\left[\mathrm{Na}_{(}\left(\mathrm{H}_{2} \mathrm{O}\right)_{6}\right]^{+}$subunits in the structure of $\mathbf{I}$.

hydrophobic surfaces and hydrophilic inner parts (Fig. 8).

The powder X-ray diffraction patterns of I and II correspond to theoretical patterns calculated from $\mathrm{X}$-ray diffraction data using the Mercury program [17] and contain no additional reflections.

According to TGA, the weight loss of the samples on heating to $350^{\circ} \mathrm{C}$ under argon is 71.4 and $61.4 \%$ for the powders of I and II, respectively. Heating of the samples is accompanied by melting followed by evaporation of water in the range of $60-100^{\circ} \mathrm{C}$, which was observed previously for the hydrates of peroxy complexes of germanium [18, 19] and tellurium [20]. According to DSC data, several exothermic effects, indicating decomposition of peroxy groups with oxygen evolution and, possibly, subsequent reactions with participation of oxygen, are recorded in the 100$130^{\circ} \mathrm{C}$ range. For comparison, the melting point of anhydrous lithium tert-butyl peroxide $\left[\left(\mathrm{LiOOCMe}_{3}\right)_{2}-\right.$ 


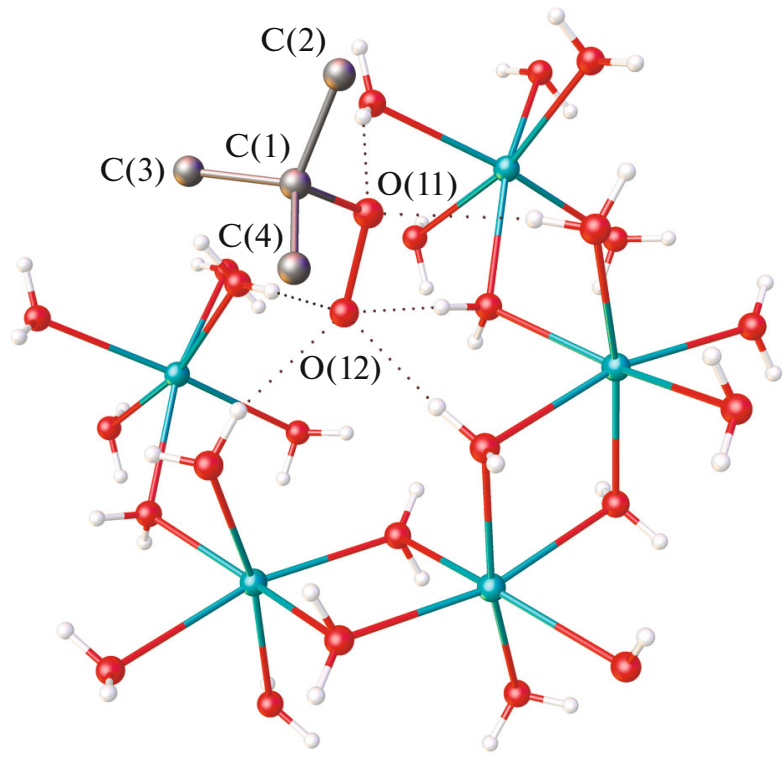

Fig. 3. Six hydrogen bonds (shown by dashed lines) formed by the organic peroxide anion in the structure of $\mathbf{I}$.
$\left(\mathrm{HOOCMe}_{3}\right)_{2}$ ] is $67^{\circ} \mathrm{C} \mathrm{[12],} \mathrm{which} \mathrm{is} \mathrm{close} \mathrm{to} \mathrm{the} \mathrm{val-}$ ues found for I and II, while THF solutions of potassium and sodium tert-butyl peroxides stabilized by NNNN-macrocycles are stable only on heating to $60^{\circ} \mathrm{C}$ [13]; however, no thermal studies of the solid products were carried out.

Thus, crystal hydrates of the tert-butyl peroxides of sodium $2 \mathrm{Na}^{+} \cdot 2 \mathrm{C}_{4} \mathrm{H}_{9} \mathrm{O}_{2}^{-} \cdot 7 \mathrm{H}_{2} \mathrm{O}$ (I) and potassium $2 \mathrm{~K}^{+} \cdot 2 \mathrm{C}_{4} \mathrm{H}_{9} \mathrm{O}_{2}^{-} \cdot 4 \mathrm{H}_{2} \mathrm{O}(\mathrm{II})$ were obtained for the first time and characterized by $\mathrm{X}$-ray diffraction. It was shown that the amphiphilic nature of tert-butyl hydroperoxide causes the formation of layered structures of I and II, in which the lyophilic and lyophobic regions alternate.

\section{ACKNOWLEDGMENTS}

X-ray diffraction measurements were performed using shared experimental facilities supported by IGIC RAS state assignment.

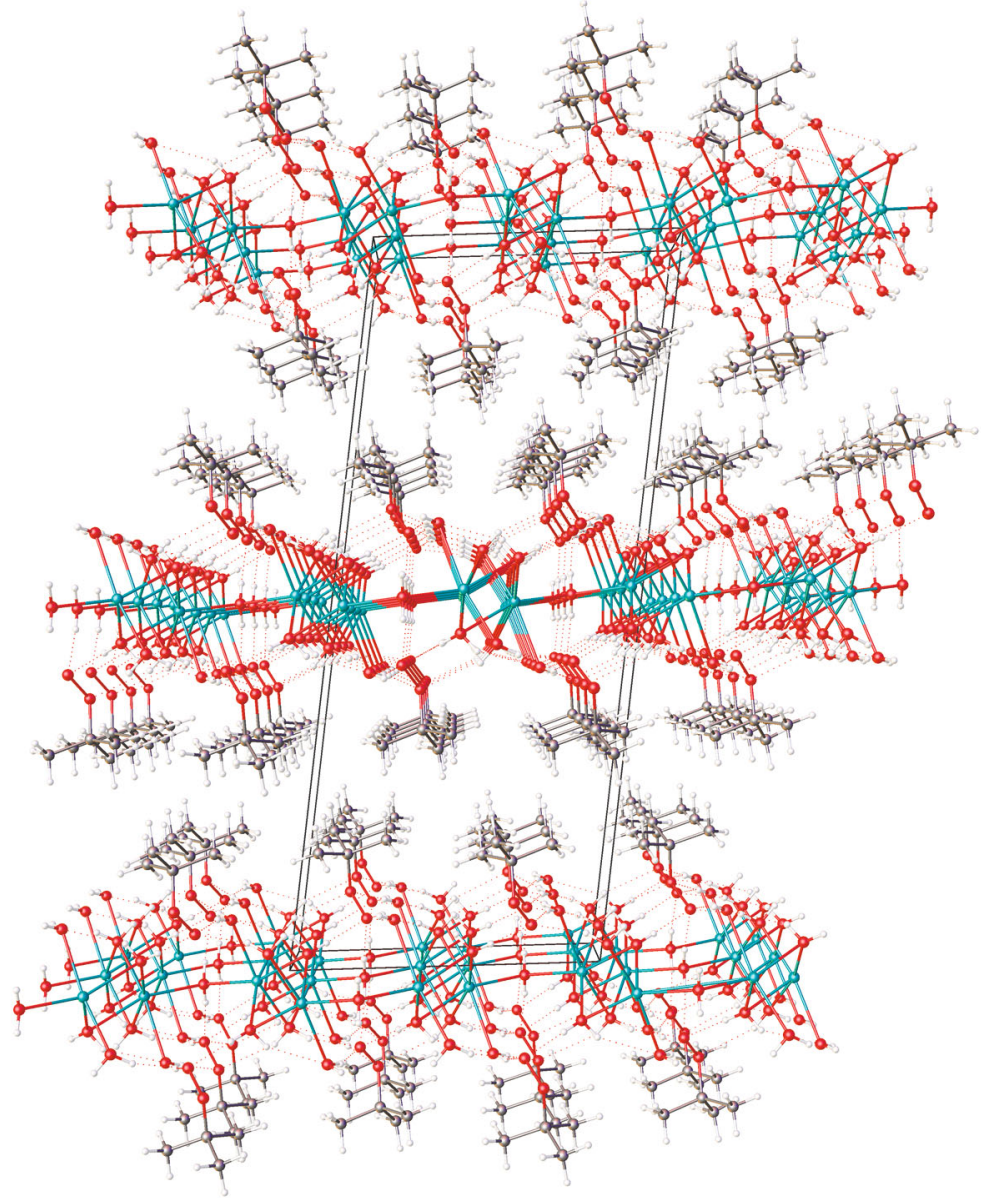

Fig. 4. Crystal packing of I. H-bonds are shown by dashed lines. 


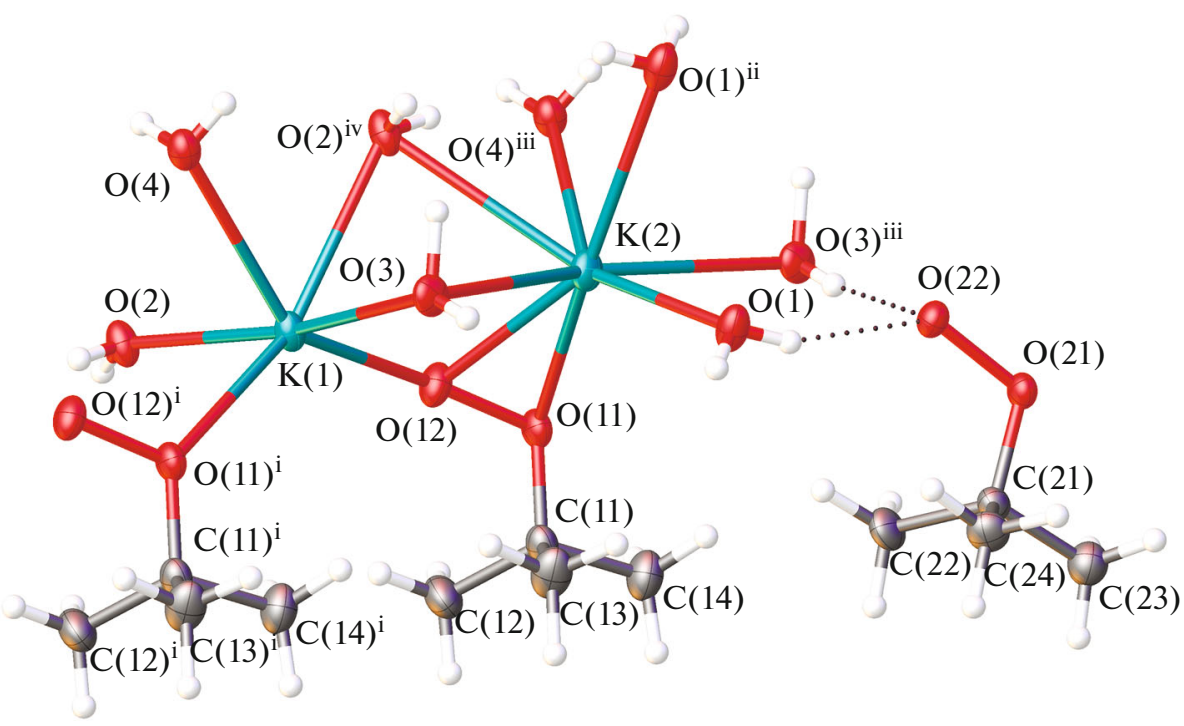

Fig. 5. Fragment of the crystal structure of II. Thermal ellipsoids are drawn at $50 \%$ probability level. H-bonds are shown by dashed lines. Symmetry codes used to generate equivalent atoms: ${ }^{\mathrm{i}} 1+x, y, z ;{ }^{\mathrm{ii}} 1-x, 1-y, 1-z ;{ }^{\text {iii }}-1+x, y, z$; ${ }^{\text {iv }} 2-x,-y, 1-z$.

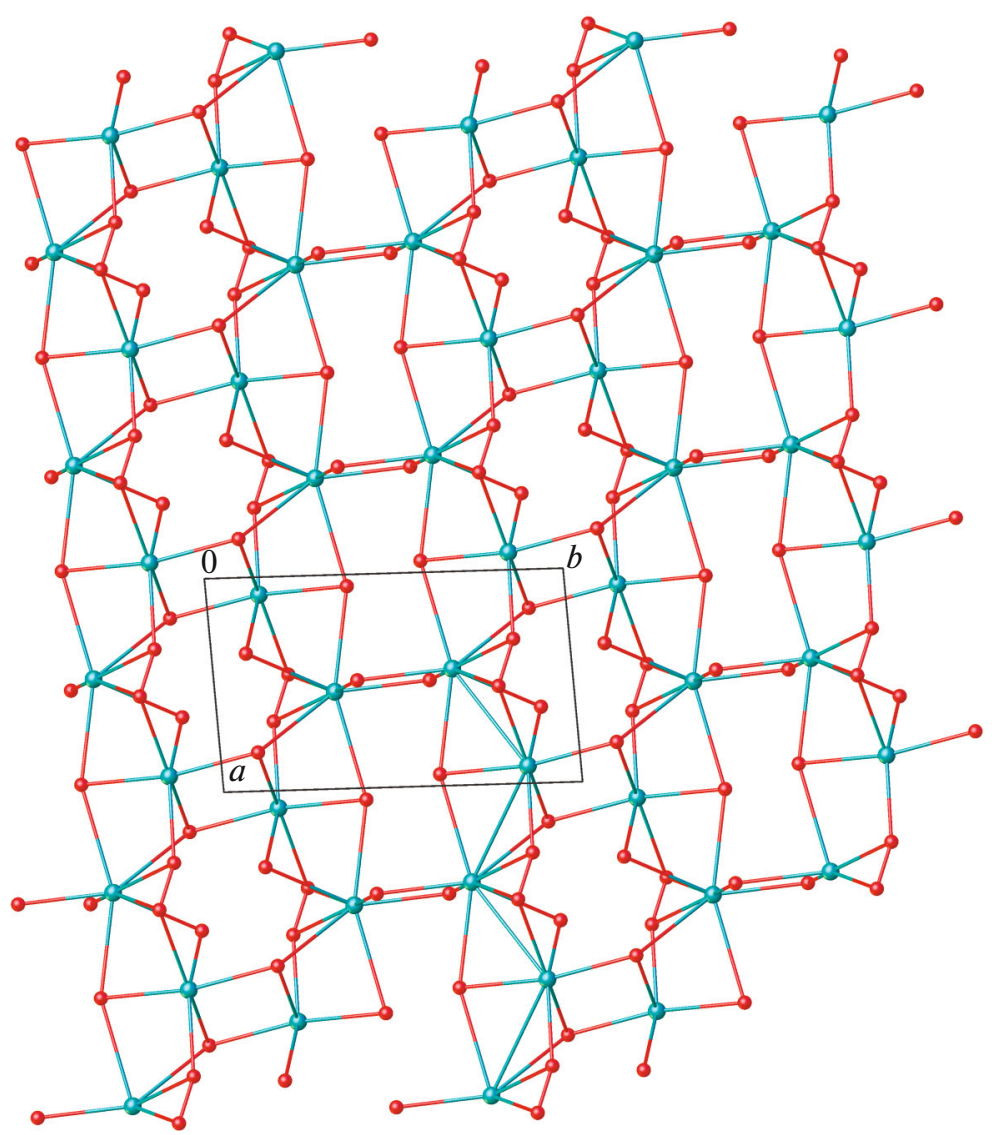

Fig. 6. Layers in the $a b$ plane formed in the structure of II by potassium-coordinated water molecules and $\mathrm{C}_{4} \mathrm{H}_{9} \mathrm{O}_{2}^{-}$anions. The carbon and hydrogen atoms are omitted for clarity. 


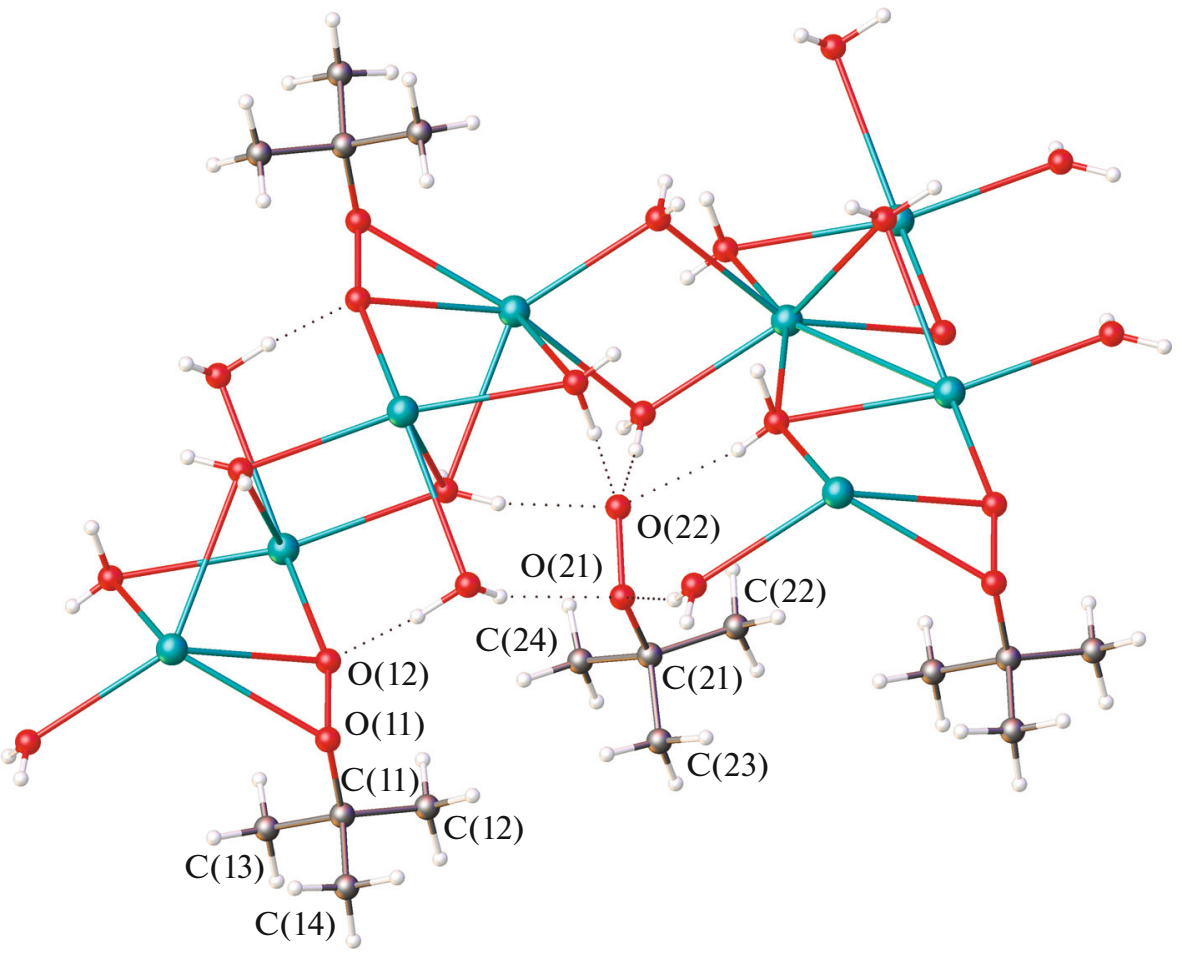

Fig. 7. Hydrogen bonds involving tert-butyl peroxide anions in II. H-bonds are shown by dashed lines.

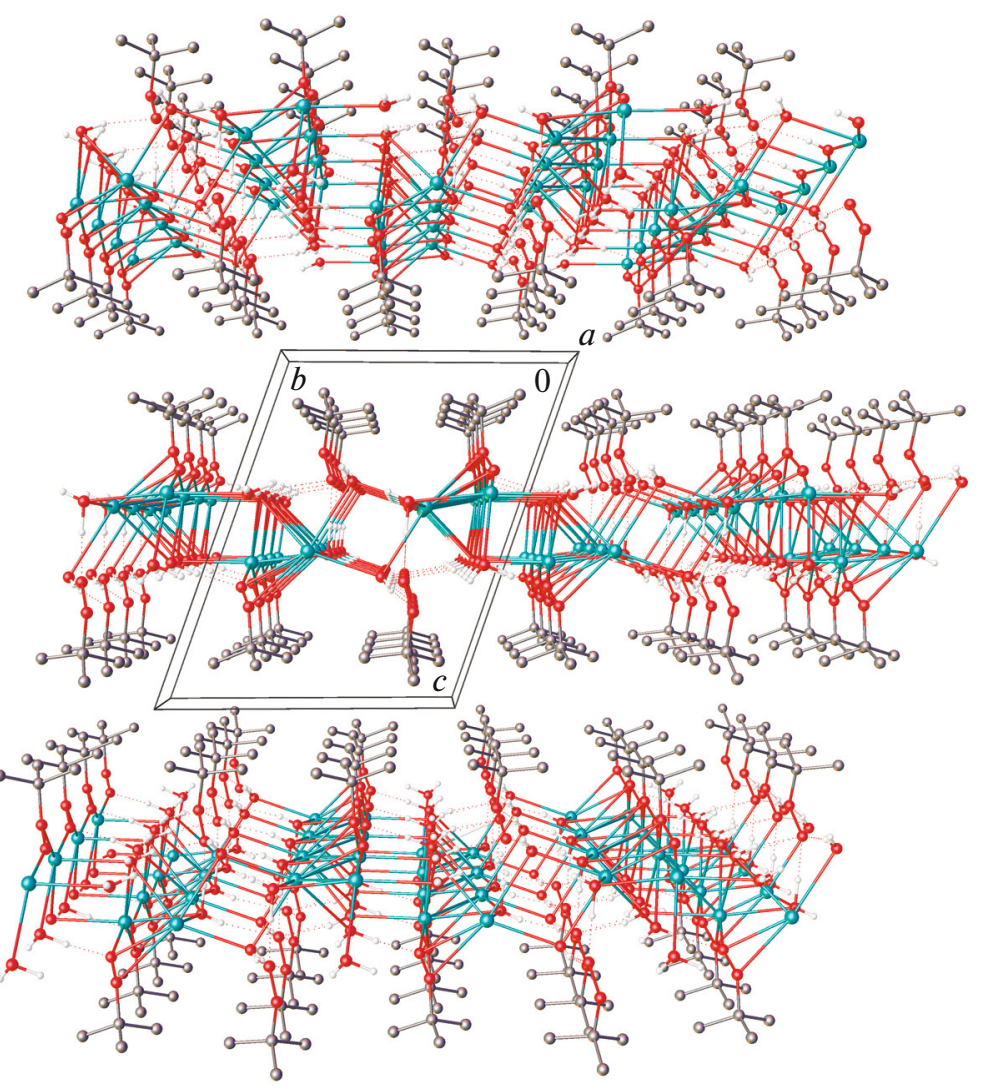

Fig. 8. Crystal packing of II. H-bonds are shown by dashed lines. 


\section{FUNDING}

This study was supported by the Russian Science Foundation (grant no. 19-73-10208).

\section{CONFLICT OF INTEREST}

The authors declare that they have no conflicts of interest.

\section{OPEN ACCESS}

This article is licensed under a Creative Commons Attribution 4.0 International License, which permits use, sharing, adaptation, distribution and reproduction in any medium or format, as long as you give appropriate credit to the original author(s) and the source, provide a link to the Creative Commons license, and indicate if changes were made. The images or other third party material in this article are included in the article's Creative Commons license, unless indicated otherwise in a credit line to the material. If material is not included in the article's Creative Commons license and your intended use is not permitted by statutory regulation or exceeds the permitted use, you will need to obtain permission directly from the copyright holder. To view a copy of this license, visit http://creativecommons.org/licenses/by/4.0/.

\section{REFERENCES}

1. Sokolov, N.A. and Aleksandrov, Yu.A., Russ. Chem. Rev., 1978, vol. 47, no. 2, p. 172. https://doi.org/10.1070/RC1978v047n02ABEH002210

2. Minko, Y. and Marek, I., Org. Biol. Chem., 2014, vol. 12 , no. 10 , p. 1535. https://doi.org/10.1039/C3OB42349B

3. Möller, M., Husemann, M., and Boche, G., J. Organomet. Chem., 2001, vol. 624, nos. 1-2, p. 47. https://doi.org/10.1016/S0022-328X(00)00596-9

4. Xia, Q.-H., Ge, H.-Q., Ye, C.-P., et al., Chem. Rev., 2005, vol. 105, no. 5, p. 1603. https://doi.org/10.1021/cr0406458

5. Porter, M.J. and Skidmore, J., Chem. Commun., 2000, no. 14 , p. 1215. https://doi.org/10.1039/B001780I

6. Elston, C.L., Jackson, R.F.W., Macdonald, S.J.F., et al., Angew. Chem., Int. Ed. Engl., 1997, vol. 36, no. 4, p. 410. https://doi.org/10.1002/anie.199704101

7. Razuvaev, G.A., Shushunov, V.A., Dodonov, V.A., and Brilklna, T.G., Organic Peroxides, New York: Wiley, 1972, vol. III.

8. Rieche, A., Dahlmann, J., and List, D., Justus Liebigs Ann. Chem., 1964, vol. 678, no. 1, p. 167. https://doi.org/10.1002/jlac.19646780118

9. Rieche, A. and Dahlmann, J., Justus Liebigs Ann. Chem., 1964, vol. 675, no. 1, p. 19. https://doi.org/10.1002/jlac.19646750104

10. Sosnovsky, G. and Brown, J.H., Chem. Rev., 1966, vol. 66 , no. 5 , p. 529. https://doi.org/10.1021/cr60243a003

11. Boche, G., Möbus, K., Harms, K., et al., Chem.-Eur. J., 1996, vol. 2, no. 5, p. 604. https://doi.org/10.1002/chem.19960020521

12. Uhl, W., Halvagar, M.R., and Claesener, M., Chem.Eur. J., 2009, vol. 15, no. 42, p. 11298. https://doi.org/10.1002/chem.200900746

13. Osseili, H., Truong, K.-N., Spaniol, T.P., et al., Chem.-Eur. J., 2017, vol. 23, no. 68, p. 17213. https://doi.org/10.1002/chem.201704758

14. SADABS. Version 2016/2. Bruker AXS Area Detector Scaling and Absorption Correction Program, Madison: Bruker AXS Inc., 2006.

15. Sheldrick, G.M., Acta Crystallogr., Sect. C: Struct. Chem., 2015, vol. 71, p. 3. https://doi.org/10.1107/S2053229614024218

16. Berry, R.E., Comprehensive Coordination Chemistry II, Pergamon, 2003, p. 625. https://doi.org/10.1016/B0-08-043748-6/01161-0

17. Macrae, C.F., Sovago, I., Cottrell, S.J., et al., J. Appl. Crystallogr., 2020, vol. 53, p. 226. https://doi.org/10.1107/S1600576719014092

18. Medvedev, A.G., Mikhaylov, A.A., Churakov, A.V., et al., Inorg. Chem., 2015, vol. 54, no. 16, p. 8058. https://doi.org/10.1021/acs.inorgchem.5b01293

19. Grishanov, D.A., Churakov, A.V., Mikhaylov, A.A., et al., Inorg. Chem., 2019, vol. 58, no. 3, p. 1905. https://doi.org/10.1021/acs.inorgchem.8b02747

20. Mikhaylov, A.A., Medvedev, A.G., Churakov, A.V., et al., Chem.-Eur. J., 2016, vol. 22, no. 9, p. 2980. https://doi.org/10.1002/chem.201503614

Translated by Z. Svitanko 